\title{
Intoxicação por Dieffenbachia seguine em bovinos
}

Gilson Antonio Pessoa ${ }^{[a]}$, Ana Paula Martini[i] ${ }^{[b]}$, Suelen Letícia dos Santos ${ }^{[a]}$, Patrícia Roberta Weber ${ }^{[a]}$, Milana Paese ${ }^{[a]}$,Vanessa de Lima $^{[a]}$, Jerbeson Hoffmann da Silva ${ }^{[a]}$ e Guilherme Novello ${ }^{[a]}$

[a] Universidade de Caxias do Sul (UCS), Caxias do Sul, RS, Brasil

${ }^{[b]}$ Programa de Pós-Graduação em Medicina Veterinária, Universidade Federal de Santa Maria (UFSM), Santa Maria, RS, Brasil

*Autor correspondente

e-mail: gilsonpessoavet@yahoo.com.br

\section{Resumo}

Existem inúmeras plantas tóxicas de fácil acesso aos animais domésticos, por isso sua ingestão é facilitada e os casos de intoxicação são frequentes. No entanto, existem outras plantas com poder tóxico cuja utilização, principalmente ornamental, impossibilita a ingestão pelos animais de interesse pecuário. Dieffenbachia seguine, popularmente conhecida como "comigo ninguém pode", é uma planta utilizada para decoração de casas e jardins. Os efeitos tóxicos desta planta não são completamente elucidados, porém já foram relatados vários casos de envenenamento pela mesma, onde a atividade inflamatória tem sido atribuída à grande quantidade do princípio tóxico cristais de oxalato de cálcio presentes nas células da planta. Os principais sinais clínicos são estomatite, sialorréia, inchaço edematoso, vômito, diarreia e dermatite de contato. 0 animal pode vir a óbito devido à asfixia que ocorre devido ao edema excessivo que provoca o fechamento da glote. A ocorrência da intoxicação ocorreu em bezerras Holandesas ( $n=8)$ com 8 meses de idade de uma propriedade rural de Dona Francisca, Rio Grande do Sul. Na anamnese constatou-se que os animais tiveram acesso acidental à planta Dieffenbachia seguine que estava no jardim da propriedade, conforme relato do proprietário, e em até 4 horas após a ingestão todos animais apresentavam alteração na cavidade oral. Os animais tiveram acesso à planta em período de privação de alimento durante o desmame. Ao exame clínico as bezerras apresentavam taquicardia, taquipneia, protusão e ulcerações na língua, assim como edema generalizado e lesões na cavidade oral e faringe. Os animais apresentavam hipertermia $\left(40,1^{\circ} \mathrm{C}\right)$. $\mathrm{O}$ exame de hemograma e bioquímico não revelaram nenhuma alteração. 0 tratamento foi baseado em fluidoterapia (500 ml/animal/dia) e água com eletrolíticos disponível para ingestão em cochos à sombra, analgésico dipirona $25 \mathrm{mg} / \mathrm{kg}$ de $12 \mathrm{em} 12$ horas por quatro dias e anti-inflamatório flunixin meglumine $1.1 \mathrm{mg} / \mathrm{kg} /$ dia durante três dias. Todos os animais apresentaram melhora clínica após sete dias do início do tratamento. 
O diagnóstico de intoxicação por Dieffenbachia seguine foi confirmado pela anamnese e sinais clínicos característicos apresentados ao exame clínico. 